\title{
Experimental Evidence for the Existence of an Iridium Sesquioxide Metastable Phase during ETEM Studies of Methane Steam Reforming on an $\mathrm{Ir} / \mathrm{Ce}_{0.9} \mathbf{G d d}_{0.1} \mathrm{O}_{2-\mathrm{x}}$ Catalyst
}

Thierry Epicier ${ }^{1}$, Mimoun Aouine ${ }^{2}$, Francisco J. Cadete Santos Aires ${ }^{2}$, Laurence Massin ${ }^{2}$ and Patrick Gélin $^{2}$

${ }^{1}$ Univ Lyon, INSA-Lyon, Université Claude Bernard Lyon 1, MATEIS, UMR 5510 CNRS, Villeurbanne Cedex, France.

${ }^{2}$ Univ Lyon, Université Claude Bernard Lyon 1, IRCELYON, UMR 5256 CNRS, Villeurbanne, France.

Solid Oxide Fuel Cells (SOFCs) are clearly one of the possible routes for domestic or industrial renewable energy cogeneration (electricity + heat) with the advantage of reducing our dependence to fossil energy sources. In this context, the anodic side of the cell can be fed with biogas, the most widespread fuel obtained from biomass and containing water vapor, methane and carbon dioxide $\mathrm{CO}_{2}$, the latter constituents being two potent greenhouse gases. Methane can be converted into hydrogen, the electrochemical oxidation of which produces water vapor and electrons, thus generating the current. Methane conversion (e.g. steam reforming of methane) is a catalytic reaction usually performed using conventional Ni-based catalysts. One main drawback of the current technologies is the production of carbon, which redeposits at the anode inlet and severely reduces the lifetime of the cell. Therefore, research of new and better catalysts is needed, and the $\mathrm{Ir} / \mathrm{Ce}_{0.9} \mathrm{Gd}_{0.1} \mathrm{O}_{2-\mathrm{x}}$ catalyst appears promising in this perspective [1].

To better understand its catalytic behavior, the system was studied in situ in the FEI Titan ETEM installed at CLYM-Lyon, F. The sample was exposed to a mixture of methane and water pressure in controlled $\mathrm{CH}_{4}: \mathrm{H}_{2} \mathrm{O}$ ratios in the range $15: 1$ to $20: 1$ and heated up to $650^{\circ} \mathrm{C}$ with a Widlfire $\mathrm{S} 5$ heating holder from DENS Solutions, using $\mathrm{Si} / \mathrm{SiN}_{\mathrm{x}}$ nanochips. A first set of results concerns observations performed typically above $600^{\circ} \mathrm{C}$ which support the hypothesis of a successful activation of the catalysts: Ir nanoparticles get covered by a stable amorphous-type layer most probably carbon-rich and most probably due to the efficient decomposition of methane at their surfaces. This shell does not evolve up to $650^{\circ} \mathrm{C}$, indicating a possible stationary regime where the deposited carbon is simultaneously partially consumed under the oxidizing action of water. During these observations, no contamination occurs on the ceria substrate ruling out interpretations involving conventional carbon contamination.

A second set of results will be presented regarding temperature cycles performed between 290 and $550^{\circ} \mathrm{C}$, where the competitive reducing and oxidizing actions of methane and water respectively lead to oscillations between the metallic phase of Ir (fcc structure, space group Fm-3m with a $=0.390 \mathrm{~nm}$, CIF \# 1534947 [2]) and the expected oxidized $\mathrm{IrO}_{2}$ structure (rutile-type structure, space group P42/mnm, tetragonal structure with $\mathrm{a}=0.45051$ and $\mathrm{c}=0.31586 \mathrm{~nm}, \mathrm{CIF} \# 1538153$ [3]). Surprisingly, a new intermediate crystalline structure appears when heating a partially oxidized particle up to its complete oxidation before a final reduction under the predominant action of methane above $480^{\circ} \mathrm{C}$ as illustrated in detail in Figure 1. Careful crystallographic indexing of diffractograms from High Resolution lattice images show that this phase is consistent with the sesquioxide structure proposed from theoretical relativistic DFT calculations (orthorhombic phase Pbna with $\mathrm{a}=5.341, \mathrm{~b}=5.514$ and $\mathrm{c}=7.399 \mathrm{~nm}$ [4]) but never confirmed experimentally so far [5]. 
References:

[1] J. Toyir et al, Catalysis Today 157 (2010), p. 451.

[2] J. Haglund et al, Phys. Rev. B 18 (1978), p. 11685.

[3] A.A. Bolzan et al, Acta Cryst. B 53 (1997), p. 373.

[4] M.S. Miao and R. Seshadri, J. Phys.: Condens. Matter 24 (2012), p. 215503.

[5] The Consortium Lyon - St-Etienne de Microscopie (CLYM www.clym.fr) is acknowledged for access to the microscope.

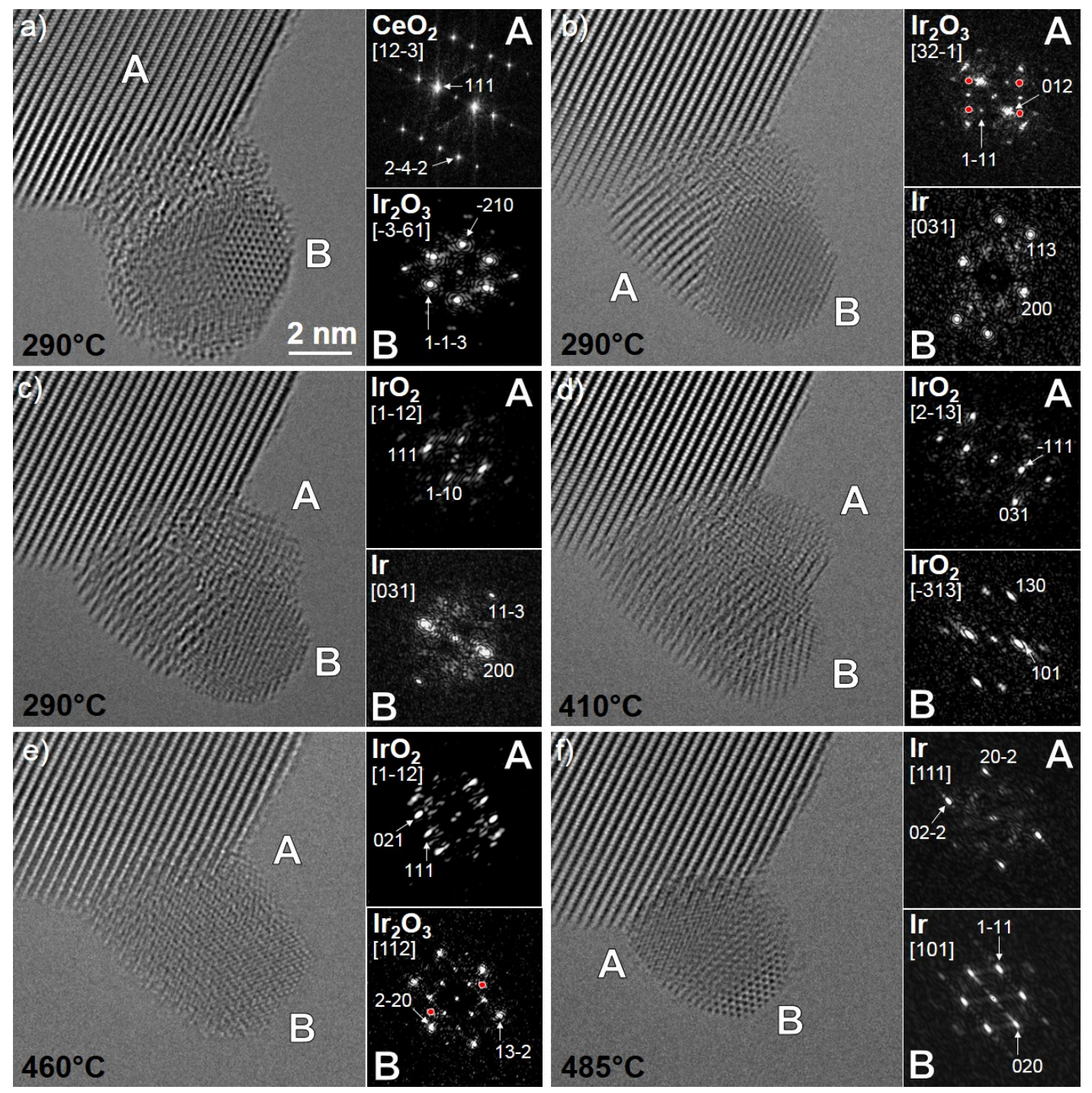

Figure 1. ETEM HRTEM images extracted from video sequences recorded under a mixture of $\mathrm{CH}_{4}: \mathrm{H}_{2} \mathrm{O}$ at pressures equal to $10^{-2}$ mbar and 1.2 mbar respectively in a-b) and c-f). In each case, diffractograms from local areas labelled A and B have been indexed using the home-made software DiffractionWorkshop (T. Epicier, unpublished). Note that the initial $\mathrm{Ir}+\mathrm{Ir}_{2} \mathrm{O}_{3}$ composite nanoparticle at $290^{\circ} \mathrm{C}$ (ab) is gradually further oxidized (c-d) before an almost complete homogenization as $\operatorname{Ir}_{2} \mathrm{O}_{3}$ at $460^{\circ} \mathrm{C}$ (e) and its final complete reduction into metallic Ir at $485^{\circ} \mathrm{C}$ (f). Red circles in b) and c) hide spurious reflections from other crystalline nano-domains. 